\title{
A curricularização da extensão universitária em um curso de formação de professores de matemática
}

Ursula Tatiana Timm*

Claudia Lisete Oliveira Groenwald**

*(Universidade Luterana do Brasil - Ulbra, Canoas, Rio Grande do Sul, Brasil)

**(Universidade Luterana do Brasil - Ulbra, Canoas, Rio Grande do Sul, Brasil)
Resumo: 0 artigo apresenta um recorte da dissertação Curricularização da extensão universitária: possibilidades em um curso de Matemática Licenciatura, realizada com o objetivo de investigar possibilidades de inserção de atividades extensionistas no currículo de um curso de Matemática Licenciatura, tendo como premissa a deliberação do Ministério de Educação de que a extensão seja incorporada em, no mínimo, 10\% do total de créditos de formação acadêmica. A pesquisa configurou-se como um estudo de natureza qualitativa, na qual foi desenvolvido um projeto de extensão com a participação de sete acadêmicos do curso de Matemática da Ulbra e 270 participantes da comunidade externa. Os resultados obtidos e as reflexões realizadas levam a considerar que uma das possibilidades viáveis para a inserção de atividades extensionistas no currículo de um curso de Licenciatura em Matemática é a modalidade de projetos de extensão.

Palavras-chave: Extensão universitária. Formação inicial de professores. Projetos extensionistas. 


\section{INTRODUÇÃO}

A universidade tem objetivos pedagógicos, sociais, políticos e culturais. Segundo Sousa (2010, p. 13), são funções da universidade: a transmissão, a produção e a extensão do saber, "sendo o ensino a função mais tradicional, pois se consubstancia na transmissão de conhecimento". Ainda segundo a pesquisadora, à universidade é também atribuída a função de socializar o saber que produz, sendo, portanto, responsabilizada pela integração social dos indivíduos.

Essa interação social entre a universidade e a comunidade, na qual a universidade compartilha conhecimentos com a comunidade e, em contrapartida, aprende com esta sobre seus valores, sua cultura e suas necessidades, constitui a extensão universitária.

O Plano Nacional de Extensão (PNExt), elaborado pelo Fórum de Pró-Reitores de Extensão das Universidades Públicas Brasileiras (Forproex) ${ }^{1}$ e pela Secretaria de Educação Superior do Ministério da Educação, apresenta objetivos, metas e estratégias para que, a partir de tais diretrizes, as universidades elaborem seus próprios planos de extensão universitária. A primeira das 11 metas apresentadas no documento, publicado em 2014, é a incorporação de, ao menos, $10 \%$ do total de horas curriculares de formação acadêmica em programas e projetos de extensão fora dos espaços de sala de aula, a fim de cumprir as exigências do Plano Nacional de Educação para o decênio 20142024 (Lei no 13.005/2014) e da Resolução no 02/2015, que estabelecem a participação da extensão no processo de integralização curricular nos cursos de graduação.

Diante dessas considerações, foram investigadas possibilidades para a inclusão de atividades extensionistas no currículo do curso de Matemática Licenciatura da Universidade Luterana do Brasil (Ulbra).

Apresenta-se, neste artigo, um recorte da dissertação de mestrado Curricularização da extensão universitária: possibilidades em um curso de Matemática Licenciatura, com as análises realizadas com a implementação

O Fórum de Pró-Reitores de Extensão trata da articulação e definição de políticas extensionistas unificadas entre as universidades públicas brasileiras. 0 objetivo é propor políticas e diretrizes básicas que permitam a institucionalização e o fortalecimento de ações comuns das Pró-Reitorias de Extensão das Instituições Públicas de Ensino Superior do Brasil. O Fórum é integrado por representantes de universidades de todas as regiões do país. 
do projeto de extensão Integrando a educação matemática na comunidade escolar com um grupo de acadêmicos da Ulbra.

1. A EXTENSÃO UNIVERSITÁRIA NA FORMAÇÃO INICIAL DE PROFESSORES DE MATEMÁTICA

Segundo Valle (1997), a finalidade da formação inicial de professores é “desenvolver os conhecimentos e competências práticas dos professores, não só para reproduzir essas práticas mas, também, para prepará-los para uma prática dinâmica, interativa e reflexiva” (apud MARTINS, 2004, p. 63).

Para Veiga (2014), os professores desempenham um conjunto de funções que ultrapassam a tarefa de ministrar aulas. Segundo a autora, "as funções formativas convencionais, como ter um bom conhecimento sobre a disciplina e como explicá-la, foram tornando-se mais complexas com o tempo e com o surgimento de novas condições de trabalho" (VEIGA, 2014, p. 24). Para Perrenoud (2001), são 11 estas competências: (1) planejar e promover situações de aprendizagem, (2) conduzir a progressão das aprendizagens, (3) conceber e fazer com que os dispositivos de diferenciação evoluam, (4) envolver os alunos em suas aprendizagens e em seu trabalho, (5) trabalhar em equipe, (6) participar da gestão da escola, (7) informar e envolver os pais, (8) utilizar tecnologias, (9) enfrentar os deveres e os dilemas éticos da profissão, (10) gerenciar sua própria formação contínua e (11) agir como um ator coletivo no sistema e direcionar o movimento rumo à profissionalização e à prática reflexiva.

Acrescenta-se ainda, que as Diretrizes Curriculares para os Cursos de Licenciatura em Matemática (BRASIL, 2001) instituem que os currículos dos cursos de Licenciatura em Matemática sejam elaborados de maneira que os licenciandos desenvolvam as competências e habilidades de:

a) expressar-se escrita e oralmente com clareza e precisão;

b) trabalhar em equipes multidisciplinares;

c) compreender, criticar e utilizar novas tecnologias para a resolução de problemas;

d) aprender continuamente, sendo sua prática profissional também fonte de produção de conhecimento;

e) habilidade de identificar, formular e resolver problemas na sua área de aplicação, utilizando rigor lógico-científico na análise da situaçãoproblema; 
f) estabelecer relações entre a Matemática e outras áreas do conhecimento;

g) conhecimento de questões contemporâneas;

h) educação abrangente necessária ao entendimento do impacto das soluções encontradas em um contexto global e social;

i) participar de programas de formação continuada;

j) realizar estudos de pós-graduação;

k) trabalhar na interface da Matemática com outros campos de saber;

l) elaborar propostas de ensino-aprendizagem de Matemática para a Educação Básica;

m) analisar, selecionar e produzir materiais didáticos;

n) analisar criticamente propostas curriculares de Matemática para a Educação Básica;

o) desenvolver estratégias de ensino que favoreçam a criatividade, a autonomia e a flexibilidade do pensamento matemático dos educandos, buscando trabalhar com mais ênfase nos conceitos do que nas técnicas, fórmulas e algoritmos;

p) perceber a prática docente de Matemática como um processo dinâmico, carregado de incertezas e conflitos, um espaço de criação e reflexão, onde novos conhecimentos são gerados e modificados continuamente, e

q) contribuir para a realização de projetos coletivos dentro da escola básica (BRASIL, 2001).

Além dessas competências e habilidades, Martinhago (2009) afirma que, para exercer adequadamente a sua atividade profissional, um professor [de matemática] deve ter bons conhecimentos de matemática, conhecer em profundidade o currículo e ser capaz de recriá-lo de acordo com a sua situação de trabalho. Nesse sentido, é muito importante que o professor de matemática conheça os conteúdos que vai ministrar nas aulas, tenha conhecimento de metodologias que são adequadas aos conteúdos e aos estudantes, saiba como os estudantes aprendem para que possa realizar um planejamento de acordo com o nível em que vai atuar. Também é importante que conheça a comunidade escolar onde vai atuar, pois, de posse desse conhecimento, terá mais chances de realizar um planejamento de acordo com a realidade, e que vá ao encontro dos anseios dos estudantes com os quais vai trabalhar.

Torna-se, portanto, fundamental, "proporcionar aos futuros professores experiências de aprendizagem através das quais comecem a definir seu papel como educadores, alargando as suas competências para além da esfera do conhecimento didático" (OLIVEIRA, 2004, p. 140).

Logo, “a formação inicial de professores deve apresentar a realidade escolar 
e a atividade profissional como fonte de situações problemas” (FERNÁNDEZ, 1998, p. 55), tendo como finalidade propor conceitos úteis e sólidos que permitam aprofundar e melhorar as atividades dos professores em formação (PINILLA, 2006).

Para Gómez (1995), a prática deve adquirir papel central de todo o currículo, assumindo-se como lugar de aprendizagem e de construção do pensamento prático do professor. Para ele, a prática realizada durante a formação inicial deve representar a realidade da aula, com as suas características de incerteza, singularidade, complexidade e conflito; por outro lado, deve proteger o futuro professor das pressões e dos riscos da aula real, que excedem a sua capacidade de assimilação e reação racional. Em suma, deve ser um espaço real onde o licenciando observa, analisa, atua e reflete sem a inteira responsabilidade da prática sobre os efeitos geralmente irreversíveis das ações (GÓMEZ, 1995).

As resoluções da legislação vigente corroboram a ideia de integração entre teoria e prática, visto que estabelecem o tempo mínimo de 400 horas para a prática de ensino como componente curricular obrigatório, 400 horas dedicadas ao estágio supervisionado na área de formação e atuação na educação básica, 200 horas de atividades teórico-práticas de aprofundamento em áreas específicas de interesse dos estudantes, por meio de iniciação científica, da iniciação à docência, da extensão e da monitoria, entre outras. o currículo deve, ainda, contemplar um mínimo de $10 \%$ do total de créditos curriculares em programas e projetos de extensão, que devem ser realizados fora da sala de aula.

Nessa perspectiva, considera-se que a atividade extensionista, que tem como característica a aproximação do acadêmico com a realidade profissional, leva à "formação de um educador comprometido com a educação, com o desenvolvimento de pesquisas na área, com a ética profissional, com o compromisso na formação de um estudante cidadão, [...] comprometido com o seu fazer pedagógico" (GROENWALD, 2005, p. 5), tornando-se um momento de construção e desenvolvimento dessas competências, propiciando um conhecimento real do exercício do magistério e uma reflexão sobre a sua escolha profissional.

Garcia, Bohn e Araújo (2013, p. 181) afirmam que "a participação em atividades de extensão promove discussões sobre como atuar nas comunidades". Os autores acreditam que essas discussões e o uso de estratégias junto à comunidade criam um fazer que integra teoria e prática, caminhando na direção da práxis, que deixa o campo da reflexão e se faz ação, preparando os 
acadêmicos para o ofício. Esse exercício desenvolve uma consciência crítica, visto que o acadêmico cria novas formas de ver o mundo. E essa consciência gera uma ação autônoma (GARCIA; BOHN; ARAÚJO, 2013).

Para esses autores, as atividades características das ações extensionistas promovem processos de desenvolvimento no indivíduo, não só em sua formação inicial, mas ao longo da sua vida profissional. Eles acreditam que as inserções, realizadas por meio de atividades de extensão universitária durante a formação inicial, oportunizam experiências prévias que ajudam a preparar os futuros profissionais para enfrentar situações reais, reduzindo as dificuldades no início da carreira profissional.

Para Síveres (2013), a extensão universitária desenvolveu um modo específico de aprender, pois há a ampliação do espaço formativo, a otimização do tempo e a significação do processo.

Com a extensão surge um "novo conceito de sala de aula, que não se limita mais ao espaço físico tradicional de ensino-aprendizagem" (BEZERRA, 2013). Segundo Bezerra (2013), nas atividades extensionistas, sala de aula são todos os espaços, dentro e fora da universidade, em que se apreende e se (re)constrói o processo histórico-social em suas múltiplas determinações e facetas. 0 estudante, assim como a comunidade com a qual se desenvolve a ação de extensão, deixa de ser mero recebedor de um conhecimento validado pelo professor para se tornar participante do processo (BEZERRA, 2013).

\section{POSSIBILIDADES DE INSERÇÃO DE ATIVIDADES EXTENSIONISTAS EM UM CURSO DE MATEMÁtica LicEnCIATURA}

Ao planejar atividades extensionistas que possam ser inseridas no currículo de um curso de formação inicial de professores de matemática, é importante compreender as modalidades de ações extensionistas determinadas nas diretrizes da Política Nacional de Extensão Universitária (FORPROEX, 2012).

Tal documento classifica as ações de extensão em cinco modalidades: programa, projeto, curso, evento e prestação de serviços, obedecendo às seguintes definições:

- Programa: conjunto articulado de projetos e outras ações de extensão (cursos, eventos), executado em médio ou longo prazo;

- Projeto: ação processual e contínua de caráter educativo, social, cultural, científico ou tecnológico, com objetivo específico e prazo 
determinado;

- Curso: ação pedagógica, de caráter teórico ou prático, planejada e organizada de modo sistemático, com carga horária mínima de oito horas e critérios de avaliação definidos;

- Evento: ação extensionista com carga-horária inferior a oito horas que implique a apresentação ou exibição pública, livre ou com clientela específica, do conhecimento desenvolvido, conservado ou reconhecido pela universidade;

- Prestação de serviço: atividades de transferência do conhecimento gerado e instalado na instituição para a comunidade.

Acredita-se que, dentre as possibilidades apresentadas quanto à inserção de atividades extensionistas no currículo de um curso de Licenciatura em Matemática, uma pode ser realizada por meio da modalidade de projetos de extensão universitária, visto que estes são considerados quando se realizam processos contínuos de caráter educativo e social, com objetivos específicos e prazos determinados. Para atingir os objetivos pedagógicos da extensão universitária, devem-se planejar projetos de extensão que sejam, também, processos de aprendizagem.

Esses projetos devem contemplar temáticas de interesse para a comunidade escolar, envolvendo, preferencialmente, pais, alunos e professores no processo de ensino e aprendizagem da matemática, sendo realizadas a difusão e a socialização do conhecimento detido na academia, produzido pelas pesquisas realizadas pelos acadêmicos.

Sugere-se desenvolver atividades como:

- Olimpíadas de Matemática.

- Feiras de Matemática - eventos para divulgar pesquisas de alunos da educação básica de determinada escola sobre a matemática e suas tecnologias.

- Clubes de Estudos de Matemática - encontros realizados em escolas a fim de promover a aprendizagem da matemática por intermédio de atividades lúdicas.

- Semanas de Matemática - eventos que contemplam atividades como palestras, minicursos e oficinas com o objetivo de promover um espaço de discussão acerca da matemática e da educação matemática.

- Oficinas pedagógicas para professores da educação básica a fim de proporcionar formação continuada para esses profissionais.

- Atividades de capacitação de alunos para as Olimpíadas brasileira e 
regionais de matemática.

- Atividades de capacitação de professores em tópicos de matemática.

- Atividades de capacitação de alunos em tópicos de matemática.

- Elaboração de revista com temas de matemática relacionados ao cotidiano da comunidade escolar.

- Desenvolvimento e aplicação de atividades de matemática na educação básica.

Com a intenção de verificar a viabilidade da curricularização da extensão em um curso de Matemática, por intermédio de projetos extensionistas, realizouse o projeto de extensão Integrando a educação matemática na comunidade escolar, efetivado com um grupo de sete acadêmicos do curso de Matemática Licenciatura, da Universidade Luterana do Brasil (Ulbra), implementando ações para que esses estudantes desenvolvessem habilidades e competências que auxiliem na compreensão da importância da divulgação dos resultados da academia para a comunidade escolar, como um compromisso social que abre caminhos para a autonomia dos indivíduos e grupos sociais, buscando viabilizar a educação como um caminho para o fortalecimento de uma nação mais forte nos princípios democráticos de justiça e de inclusão.

\section{Metodologia da Pesquisa}

A temática investigada foi a curricularização da extensão, isto é, a inserção de atividades extensionistas no currículo de um curso de graduação. 0 problema da pesquisa foi: Quais as possibilidades de inclusão de atividades de extensão universitária no currículo do curso de Licenciatura em Matemática da Universidade Luterana do Brasil (Ulbra)?

Considerando a temática e o problema de pesquisa, bem como o objetivo geral proposto, que era investigar possibilidades acadêmicas para a inclusão da extensão universitária no currículo do curso de Matemática Licenciatura da Ulbra, a fim de cumprir as exigências do Plano Nacional de Educação para o decênio 2014-2024, optou-se por realizar uma pesquisa qualitativa, pois, de acordo com André (1983), esse tipo de abordagem traz a vantagem de se poder trabalhar com dados que são de difícil quantificação, sendo possível então buscar captar os significados que compõem a experiência vivida pelos sujeitos envolvidos na pesquisa, visando compreender as relações entre os indivíduos, seu contexto e suas ações.

A pesquisa foi caracterizada como um estudo de caso, pois propôs a realização de um experimento no curso de Matemática da Ulbra, investigando 
possibilidades de inserir atividades de extensão universitária no currículo desse curso, com a pretensão de que os acadêmicos desenvolvam habilidades e competências que contribuam para a sua formação. Segundo Merrian (apud DEUS; CUNHA; MACIEL, 2010), “o conhecimento gerado por esse tipo de pesquisa é mais concreto, mais contextualizado, mais voltado para a interpretação do pesquisador e baseado em populações de referência determinadas pelo próprio pesquisador".

O desenvolvimento da pesquisa contemplou, de forma integrada, ações de:

- investigação das concepções dos alunos sobre extensão universitária e o grau de comprometimento destes, com divulgação dos conhecimentos adquiridos na universidade para a comunidade escolar. Essa investigação foi realizada por meio de um questionário de pesquisa (em formato digital, via ferramenta Google Docs) enviado para todos os acadêmicos matriculados no curso de Licenciatura em Matemática da Ulbra, no segundo semestre letivo do ano de 2016. $\mathrm{Na}$ época, o curso contava com 305 alunos, dos quais apenas 69 responderam à pesquisa.

- investigação, por meio de pesquisa teórica, de ações a ser utilizadas em uma atividade de extensão universitária a ser realizada na formação inicial de professores de matemática no curso de Licenciatura em Matemática da Ulbra.

- implementação (desenvolvimento, aplicação e avaliação) de atividades extensionistas com estudantes do curso de Licenciatura em Matemática da Ulbra. Nessa etapa foi realizado o projeto de extensão Integrando a educação matemática com a comunidade escolar com um grupo de sete acadêmicos do curso de Licenciatura em Matemática da Ulbra, sendo quatro da modalidade de ensino presencial e três da modalidade de ensino a distância. Para a instrumentalização e acompanhamento das atividades realizadas pelos acadêmicos foi utilizado o Ambiente Virtual de Aprendizagem (AVA), próprio da universidade, denominado NetAula.

- investigação para verificar se a participação no projeto de extensão gerou mudanças em relação às concepções sobre a extensão universitária e no grau de comprometimento dos acadêmicos, com a divulgação dos conhecimentos adquiridos na universidade para a comunidade escolar. Essa investigação foi realizada por intermédio de um questionário para os sete acadêmicos participantes do projeto de extensão realizado. 
Como resultado do projeto de extensão implementado, foram realizadas cinco ações extensionistas com a participação de sete acadêmicos do curso de Matemática Licenciatura da Ulbra, envolvendo 270 participantes da comunidade externa.

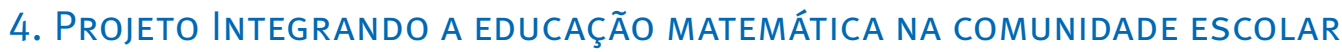

No estudo de caso, foi implementado o projeto de extensão denominado Integrando a educação matemática na comunidade escolar, que se caracterizou pelo desenvolvimento e aplicação de atividades de matemática, compreendendo capacitação inicial dos acadêmicos participantes do projeto sobre as temáticas Extensão Universitária e Formação Inicial de Professores; atividades de pesquisa e discussões sobre as atividades e temáticas escolhidas pelos estudantes; desenvolvimento de atividades e construção de material didático para aplicação nas oficinas pedagógicas; planejamento e realização de oficinas pedagógicas ${ }^{2}$ para professores de instituições de ensino básico ou sequências didáticas ${ }^{3}$ desenvolvidas com estudantes do ensino básico.

As oficinas pedagógicas são espaços de reflexão e aprendizagem coletiva sobre a prática pedagógica. Nesses espaços, os acadêmicos terão a oportunidade de desenvolver competências e habilidades para atuar na sua vida profissional.

3 Sequência didática é uma sequência elaborada pelo professor que proporciona uma organização das atividades a serem realizadas pelo aluno a fim de explorar o domínio de seu conhecimento. 
As ações extensionistas realizadas estão descritas no Quadro 1.

Quadro 1 - Ações extensionistas

Ação extensionista 1: Utilizando a tecnologia em pesquisas estatísticas

Local: Escola Técnica Estadual Portão - Portão - RS

Público envolvido: 23 alunos do 3 ำ ano do ensino médio

Objetivo: Desenvolver o ensino da estatística com o uso de recursos tecnológicos.

Descrição: Esta ação foi realizada em uma turma que estava trabalhando o conteúdo de distribuição de frequências e gráficos estatísticos. A proposta foi a realização de pesquisas estatísticas com o uso da tecnologia. Para tanto, foi utilizada a ferramenta formulário do Google Docs, na criação e aplicação dos questionários, e o software Power Point para as apresentações dos resultados.

Conteúdos envolvidos no projeto: Distribuição de frequências, gráficos estatísticos e medidas de tendência central.

Ação extensionista 2: A ludicidade no processo de ensino e aprendizagem

Local: Emef Marechal Cândido Rondon - Três Coroas - RS

Público envolvido: 18 profissionais da educação, entre professores de educação infantil e anos iniciais do ensino fundamental e equipe diretiva

Objetivo da atividade: Proporcionar, aos professores, experiências concretas do uso de atividades lúdicas no ensino da matemática para estudantes de educação infantil e anos iniciais.

Descrição: Foi realizada oficina pedagógica abordando questões de aprendizagem e desenvolvimento dos alunos em matemática, o uso do lúdico no cotidiano escolar, seus benefícios e de que forma pode ser trabalhado. Divididos em grupos, os participantes jogaram e discutiram a utilidade das atividades propostas, bem como sugeriram adaptações a serem feitas de acordo com o perfil de cada turma.

Conteúdos envolvidos no projeto: Formas geométricas, seriação, classificação, operações com números naturais, ordem crescente e decrescente, frações e divisibilidade. 
Ação extensionista 3: Oficina pedagógica no Polo Conquistadora

Local: Escola Conquistadora - Polo EAD Ulbra - Novo Hamburgo - RS

Público envolvido: 38 participantes, sendo seis professores do ensino fundamental e 32 futuros professores de cinco instituições de ensino superior.

Objetivo da atividade: Proporcionar, aos professores e futuros professores, experiências concretas do uso de atividades lúdicas no ensino da matemática.

Descrição: Foi ministrada oficina sobre o uso de atividades lúdicas no ensino da matemática. Nessa oficina, discutiu-se a importância do uso de jogos e atividades lúdicas no ensino de matemática e foram apresentadas e praticadas atividades como: Torre de Hanói, dominós, origamis e a demonstração da construção de uma pipa (pandorga) tetraédrica.

Conteúdos envolvidos no projeto: Formas geométricas, ordem crescente, operações com números naturais, frações (representação e comparação), monômios, área e perímetro de polígonos.

Ação extensionista 4: Projeto Eu Cientista - Conhecendo a Matemática

Local: Colégio Ulbra Cristo Redentor - Canoas - RS

Público envolvido: 63 alunos da educação infantil

Objetivos: Estimular a criatividade e a imaginação das crianças por meio de contação de história, proporcionar de forma lúdica a aprendizagem das formas geométricas, desmitificar a ideia de que a matemática é uma disciplina difícil e “chata”.

Descrição: Os acadêmicos extensionistas realizaram as seguintes atividades: (1) Boas-vindas e apresentação dos ministrantes da atividade; (2) Contação da história "Conhecendo a Matemática"; (3) Twister das Formas; (4) Completando as figuras; (5) Quebra-cabeça das formas e (6) Fechamento.

Conteúdos envolvidos no projeto: Formas geométricas. 
Ação extensionista 5: Circuito Matemático

Local: Emef Engenheiro Ildo Meneghetti - Canoas - RS

Comunidade: 128 alunos dos $6^{\circ}$ s e $7^{\circ}-5$ anos do ensino fundamental

Objetivos: Proporcionar de forma lúdica a aprendizagem de conceitos matemáticos, desmitificando a ideia de que a matemática é uma disciplina difícil.

Descrição: Os acadêmicos organizaram um Circuito Matemático, com atividades envolvendo frações e operações básicas com números naturais e inteiros. Nesse circuito, os alunos, divididos em grupos, foram convidados a realizar nove atividades diferentes no menor tempo possível.

Conteúdos envolvidos no projeto: Formas geométricas, comparação de números naturais, valor absoluto, valor relativo, operações com números naturais, frações (definição, representação, comparação e operações), número misto, expressões numéricas, comparação de números inteiros e números primos.

Fonte: Elaborado pelos autores.

Os acadêmicos apresentaram propostas de ações extensionistas condizentes com a escolha de cada comunidade em que iriam atuar (por exemplo, para a ação extensionista realizada com alunos da educação infantil, foram elaboradas atividades respeitando os limites cognitivos dessa faixa etária), o que, segundo D’Ambrósio (2001), é característica de um bom profissional em educação matemática.

É importante destacar que a realização de cinco ações extensionistas, por um grupo de sete acadêmicos, possibilitou a integração da escola com a universidade, levando conhecimento para um grupo de 270 indivíduos da comunidade externa (comunidade escolar),

Para elucidar a participação dos acadêmicos nesse projeto de extensão, descreve-se a ação extensionista Circuito Matemático.

\subsection{Ação extensionista Circuito Matemático}

Essa ação foi realizada por dois acadêmicos da modalidade de ensino 
presencial em uma escola municipal de ensino fundamental do município de Canoas, no estado do Rio Grande do Sul, com 128 estudantes dos $6{ }^{\circ}$ s e $7^{\circ} \stackrel{\circ}{s}$ anos.

O objetivo dessa ação foi proporcionar de forma lúdica a ampliação da aprendizagem de conceitos matemáticos, desmitificando a ideia de que a matemática é uma disciplina difícil e que os estudantes devem aprendê-la de forma individual e em silêncio, sem interação social.

Dessa forma, os acadêmicos organizaram um Circuito Matemático, com atividades envolvendo frações e operações básicas com números naturais e números inteiros. Nesse circuito, os alunos seriam divididos em grupos e convidados a realizar nove atividades diferentes no menor tempo possível. $O$ encontro dos acadêmicos com cada uma das quatro turmas atendidas durou, aproximadamente, uma hora e 50 minutos, e os estudantes do ensino fundamental tiveram uma hora e 30 minutos para realizar as nove atividades propostas.

As atividades selecionadas pelos extensionistas foram:

(1) Labirinto dos números primos

Nesta atividade, os estudantes deveriam encontrar o caminho da "entrada" até a "saída" (Figura 1), passando apenas por números primos e deslocandose apenas nos sentidos laterais (direita e esquerda) e para baixo. 
Figura 1 - Labirinto dos números primos

\begin{tabular}{|c|c|c|c|c|c|c|c|c|c|c|c|c|c|c|c|c|c|c|c|}
\hline 2 & 1 & 1 & 3 & 4 & 1 & 9 & 2 & 7 & 5 & 2 & 2 & 1 & 1 & 2 & 1 & 7 & 5 & 2 & 3 \\
\hline 1 & 2 & 1 & 1 & 4 & 2 & 2 & 5 & 3 & 2 & 3 & 2 & 1 & 1 & 2 & 1 & 1 & 3 & 5 & 7 \\
\hline 2 & 8 & 1 & 3 & 1 & 5 & 1 & 2 & 3 & 3 & 7 & 2 & 4 & 2 & 1 & 4 & 9 & 7 & 5 & 7 \\
\hline 1 & 7 & 5 & 3 & 2 & 7 & 5 & 3 & 1 & 7 & 9 & 3 & 1 & 5 & 4 & 1 & 2 & 7 & 1 & 1 \\
\hline 2 & 2 & 1 & 1 & 3 & 1 & 9 & 3 & 7 & 1 & 3 & 2 & 2 & 1 & 4 & 1 & 5 & 2 & 1 & 2 \\
\hline 3 & 4 & 2 & 2 & 5 & 7 & 1 & 2 & 9 & 2 & 3 & 2 & 2 & 3 & 1 & 7 & 2 & 2 & 2 & 1 \\
\hline 5 & 7 & 1 & 1 & 2 & 1 & 8 & 1 & 1 & 9 & 5 & 1 & 7 & 5 & 1 & 9 & 4 & 2 & 2 & 2 \\
\hline 7 & 1 & 2 & 1 & 3 & 2 & 9 & 1 & 2 & 1 & 7 & 2 & 1 & 7 & 1 & 1 & 5 & 7 & 9 & 1 \\
\hline 1 & 1 & 1 & 2 & 5 & 7 & 1 & 1 & 1 & 9 & 1 & 1 & 2 & 4 & 9 & 2 & 1 & 1 & 2 & 1 \\
\hline 2 & 4 & 2 & 1 & 7 & 3 & 5 & 5 & 2 & 3 & 5 & 7 & 4 & 3 & 1 & 3 & 2 & 2 & 1 & 1 \\
\hline 2 & 3 & 4 & 1 & 2 & 1 & 2 & 5 & 3 & 1 & 1 & 1 & 1 & 1 & 1 & 2 & 3 & 2 & 1 & 2 \\
\hline 2 & 1 & 5 & 4 & 4 & 1 & 1 & 7 & 2 & 5 & 4 & 3 & 1 & 3 & 7 & 2 & 5 & 7 & 1 & 1 \\
\hline 1 & 1 & 7 & 7 & 2 & 2 & 1 & 5 & 3 & 7 & 7 & 5 & 3 & 2 & 3 & 9 & 7 & 1 & 9 & 1 \\
\hline 1 & 2 & 1 & 9 & 4 & 2 & 4 & 2 & 2 & 2 & 1 & 1 & 7 & 5 & 7 & 1 & 1 & 1 & 1 & 1 \\
\hline 2 & y & 1 & 9 & 3 & 2 & 2 & 3 & 5 & 4 & 1 & 4 & 1 & 7 & 1 & 1 & 1 & 3 & 3 & 2 \\
\hline 7 & 1 & 4 & 2 & 1 & 7 & 1 & 1 & 7 & 2 & 4 & 1 & 9 & 2 & 2 & 7 & 5 & 2 & 3 & 2 \\
\hline 1 & 9 & 4 & 4 & 4 & 1 & 1 & 9 & 2 & 2 & 4 & 2 & 1 & 1 & 1 & 4 & 3 & 7 & 5 & $\mathbf{I}$ \\
\hline 9 & 1 & 2 & 3 & 3 & 1 & 1 & 3 & 2 & 2 & 4 & 5 & 7 & 1 & 1 & 1 & 1 & 1 & 7 & 9 \\
\hline 2 & 1 & 5 & 3 & 3 & 2 & 2 & 1 & 1 & 7 & 5 & 3 & 2 & 2 & 2 & 7 & 9 & 1 & 2 & 2 \\
\hline 1 & 1 & 7 & 5 & 2 & 2 & 1 & 1 & 1 & 9 & 7 & 5 & 3 & 1 & 2 & 3 & 4 & 1 & 1 & 2 \\
\hline 1 & 2 & 1 & 2 & 3 & 4 & 2 & 3 & 1 & 1 & 9 & 1 & 1 & 1 & 1 & 1 & 2 & 2 & 1 & 2 \\
\hline 1 & 2 & 1 & 3 & 4 & 5 & 3 & 2 & 2 & 1 & 1 & 3 & 4 & 9 & 1 & 2 & 3 & 3 & 2 & 2 \\
\hline 2 & 1 & 2 & 5 & 7 & 1 & 1 & 1 & 9 & 1 & 4 & 1 & 1 & 2 & 3 & 7 & 1 & 9 & 2 & 3 \\
\hline 1 & 3 & 1 & 4 & 1 & 1 & 1 & 1 & 2 & 2 & 4 & 4 & 2 & 5 & 4 & 2 & 1 & 1 & 2 & 4 \\
\hline 5 & 1 & 1 & 4 & 1 & 2 & 1 & 3 & 2 & 3 & 3 & 2 & 3 & 1 & 9 & 1 & 3 & 3 & 1 & 1 \\
\hline 2 & 2 & 2 & 3 & 1 & 1 & 7 & 5 & 2 & 3 & 1 & 5 & 5 & 7 & 1 & 1 & 1 & 1 & 3 & 2 \\
\hline 2 & 4 & 5 & 1 & 3 & 1 & 2 & 4 & 4 & 4 & 7 & 2 & 1 & 1 & 1 & 2 & 1 & 2 & 2 & 2 \\
\hline 3 & 3 & 2 & 3 & 2 & 2 & 1 & 1 & 1 & 2 & 3 & 5 & 7 & 1 & 5 & 2 & 4 & 3 & 3 & 3 \\
\hline 1 & 1 & 1 & 1 & 7 & 1 & 1 & 1 & 2 & 1 & 1 & 1 & 1 & 7 & 5 & 3 & 2 & 4 & 7 & 5 \\
\hline 2 & 2 & 1 & 7 & 4 & 4 & 3 & 3 & 2 & 2 & 4 & 2 & 4 & 2 & 7 & 7 & 1 & 1 & 1 & 5 \\
\hline 1 & 7 & 5 & 3 & 2 & 3 & 1 & 3 & 2 & 1 & 2 & 3 & 7 & 1 & 1 & 3 & 3 & 3 & 3 & 4 \\
\hline 1 & 1 & 1 & 1 & 1 & 2 & 2 & 3 & 3 & 4 & 4 & 3 & 5 & 5 & 7 & 1 & 1 & 2 & 2 & 3 \\
\hline 5 & 7 & 1 & 2 & 3 & 4 & 2 & 1 & 5 & 2 & 4 & 4 & 2 & 4 & 2 & 2 & 3 & 1 & 2 & 3 \\
\hline
\end{tabular}

Fonte: Elaborada pelos autores.

Os estudantes do 60 ano apresentaram dificuldade ao realizar essa atividade por não terem construído o conceito de número primo. Muitos grupos necessitaram de auxílio dos acadêmicos extensionistas para a conclusão dessa atividade. 
(2) Tangram

O Tangram é um quebra-cabeça geométrico de origem chinesa, formado por sete peças: dois triângulos isósceles grandes, dois triângulos isósceles pequenos, um triângulo isóscele médio, um quadrado e um paralelogramo.

Nessa atividade, os estudantes deveriam formar um quadrado utilizando todas as sete peças do quebra-cabeça, sem sobrepô-las.

(3) Tangram - versão digital

$\mathrm{Na}$ terceira atividade selecionada, os estudantes deveriam formar dois desenhos no Tangram, acessando tal aplicativo em um tablet. O Tangram é uma versão digital do quebra-cabeça de mesmo nome, descrito na atividade anterior. Esta versão permite a construção de uma grande variedade de figuras a partir das sete peças do Tangram, que podem ser rotadas, refletidas, giradas e transladadas.

(4) Duelo matemático

Em dupla, os estudantes deveriam jogar duas partidas de nível médio de Math Duel, um jogo que inclui operações matemáticas básicas (adição, subtração, multiplicação e divisão) e no qual o vencedor é o jogador que realizar os cálculos mentais mais rapidamente.

A interface do Math Duel é um tabuleiro dividido ao meio, no qual os jogadores devem realizar a operação indicada e selecionar a resposta correta dentre as três possibilidades de respostas indicadas pelo aplicativo.

(5) Simply Fractions

Simply Fractions é um aplicativo disponível para Android que apresenta atividades envolvendo frações e números decimais. Nesta atividade, os alunos deveriam realizar atividades que envolviam representação geométrica, fracionária e decimal de números racionais, e comparação de frações e números decimais.

(6) Régua de frações

Nesta atividade, os grupos deveriam organizar as peças da régua de frações (Figura 2) e utilizá-la para comparar frações. 
Figura 2 - Régua de frações

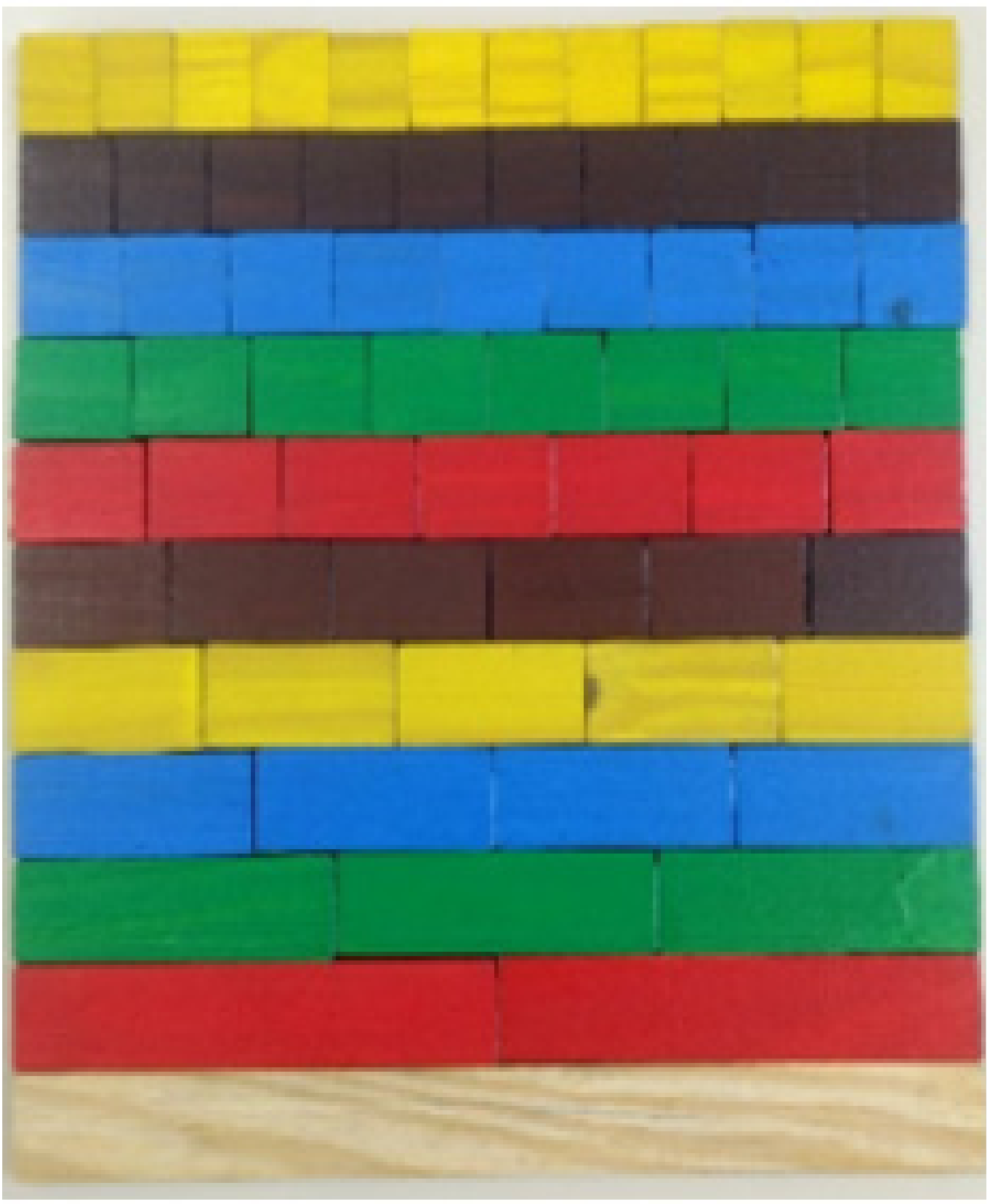

Fonte: Elaborada pelos autores.

(7) Atividade ludo-pedagógica

Na sétima atividade selecionada, os estudantes deveriam completar as frases indicadas (Figura 3) e, em seguida, ligar os pontos correspondentes às respostas encontradas, conforme a ordem alfabética das afirmativas apresentadas, formando uma figura. 
Figura 3 - Atividade ludo-pedagógica

Complete os espaços nas frases seguintes e, à medida que for achando as respostas, ligue os pontos correspondentes às respostas no pontilhado abaixo. No final formará uma figura. Que figura é essa?

- O menor número natural não nulo é

- O sucessor par do número 13 é

- O valor da potência 24 é

- O resultado ou quociente de 12111 é

- 625 vale

- O valor da expressão 24 - 20 é

- Um número elevado ao quadrado dá 49; esse número é

- O valor da expressão (642-100)+10 é

- $\quad$ único número da sequência: $1,4,9,16,23,36$ que não é quadrado perfeito é

- Os números 2, 12, 21, 78, 1890, 1894626 são divisíveis por dois, exceto

- Um número n elevado ao cubo vale 64; o número n é

- O valor da expressão $52+2$ é

- O cubo do número 2 vale

- $\quad 0$ número de elementos do conjunto $M=\left\{x N^{\star} \mid x<3\right\}$ é

- A raiz quadrada do valor da expressão $25+2(33: 9-1)$ é

- A metade do valor da expressão $24:(7.3-5)+(33+23): 7$ é

- O valor da expressão 52 - 1 é .W

- O dobro de 81 é

- Um número escrito na base 2 é 10011; na base 10 vale

- O antecessor do número 11 é

- O dobro do sucessor do número 10 é

- O valor absoluto do algarismo 9 no número 18809 é

- O valor relativo do algarismo 2 no número 14620 é

- Entre os números 14, 17, 16, 5, o único divisível por 5 é

- $\quad 0$ valor da expressão $20-(6+4-7)$ é

- Do número 2000, você subtrai 1280. A seguir, divide o resultado por 5. A raiz quadrada do número que você obteve é igual a

Fonte: COELHO, Mozart Cavazza Pinto. Revista do Professor de Matemática, SBM, n. 33, 1997.

Os estudantes do $6^{\circ}$ e do $7^{\circ}$ ano apresentaram dificuldade ao realizar esta atividade, em especial nas questões "n" e "s", que tiveram de ser respondidas pelos acadêmicos extensionistas, visto que os alunos demonstraram não ter 
conhecimento sobre notações de conjuntos e representação de um número em diferentes bases.

(8) Igualdades matemáticas

$\mathrm{Na}$ atividade igualdades matemáticas, os estudantes deveriam inserir os sinais aritméticos nas igualdades apresentadas (Figura 4), de forma que estas fossem verdadeiras.

Figura 4 - Igualdades matemáticas

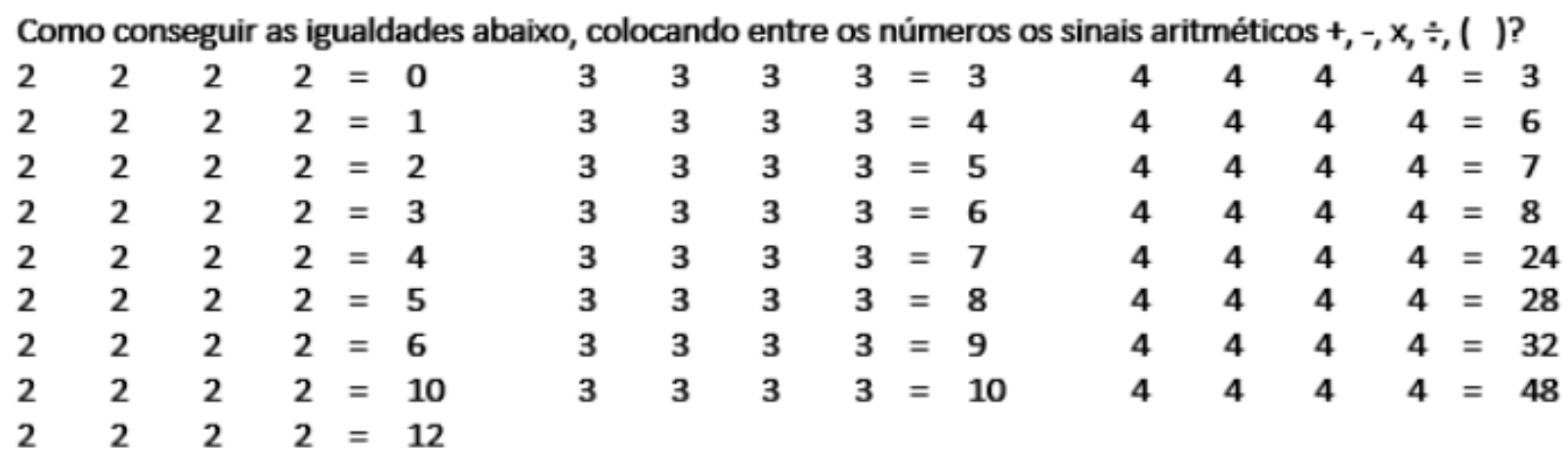

Fonte: Elaborado pelos autores.

Os estudantes completaram com facilidade as igualdades que não necessitavam do uso de parênteses. Poucos grupos concluíram esta atividade.

(9) Labirinto dos inteiros

No labirinto dos inteiros (Figura 5), os estudantes deveriam iniciar o labirinto no “+10", posicionado no canto superior esquerdo, e chegar ao “-10", posicionado no canto inferior direito, seguindo apenas na horizontal ou na vertical, passando de um número para outro menor. 
Figura 5 - Labirinto dos inteiros

\section{LABIRINTO DOS INTEIROS}

Você deve começar pela casa superior esquerda e acabar na casa inferior direita. Pode andar no sentido horizontal e vertical, mas nunca na diagonal. Não esqueça: você deve passar de um número para outro menor!!!

\begin{tabular}{lllllll}
+10 & -1 & +7 & 0 & +5 & -4 & -3 \\
+9 & +8 & -8 & +6 & 0 & +4 & +3 \\
-2 & -5 & +7 & +9 & -3 & +2 & -2 \\
+9 & -1 & +2 & +9 & +1 & -3 & -1 \\
+7 & -2 & +5 & 0 & +8 & -4 & -5 \\
-3 & +6 & -1 & +8 & +7 & -8 & -9 \\
4 & -5 & -6 & -7 & -8 & -9 & -10 \\
\hline
\end{tabular}

Fonte: Elaborada pelos autores.

Os estudantes desenvolveram esta atividade com facilidade, inclusive os alunos do 6ำ ano, que ainda não haviam estudado o conjunto dos números inteiros.

Nas imagens a seguir (Figura 6), apresentam-se momentos de realização das atividades pelos alunos dos $6^{\circ}$ s e $70^{\circ}$ s anos.

Figura 6 - Alunos desenvolvendo as atividades

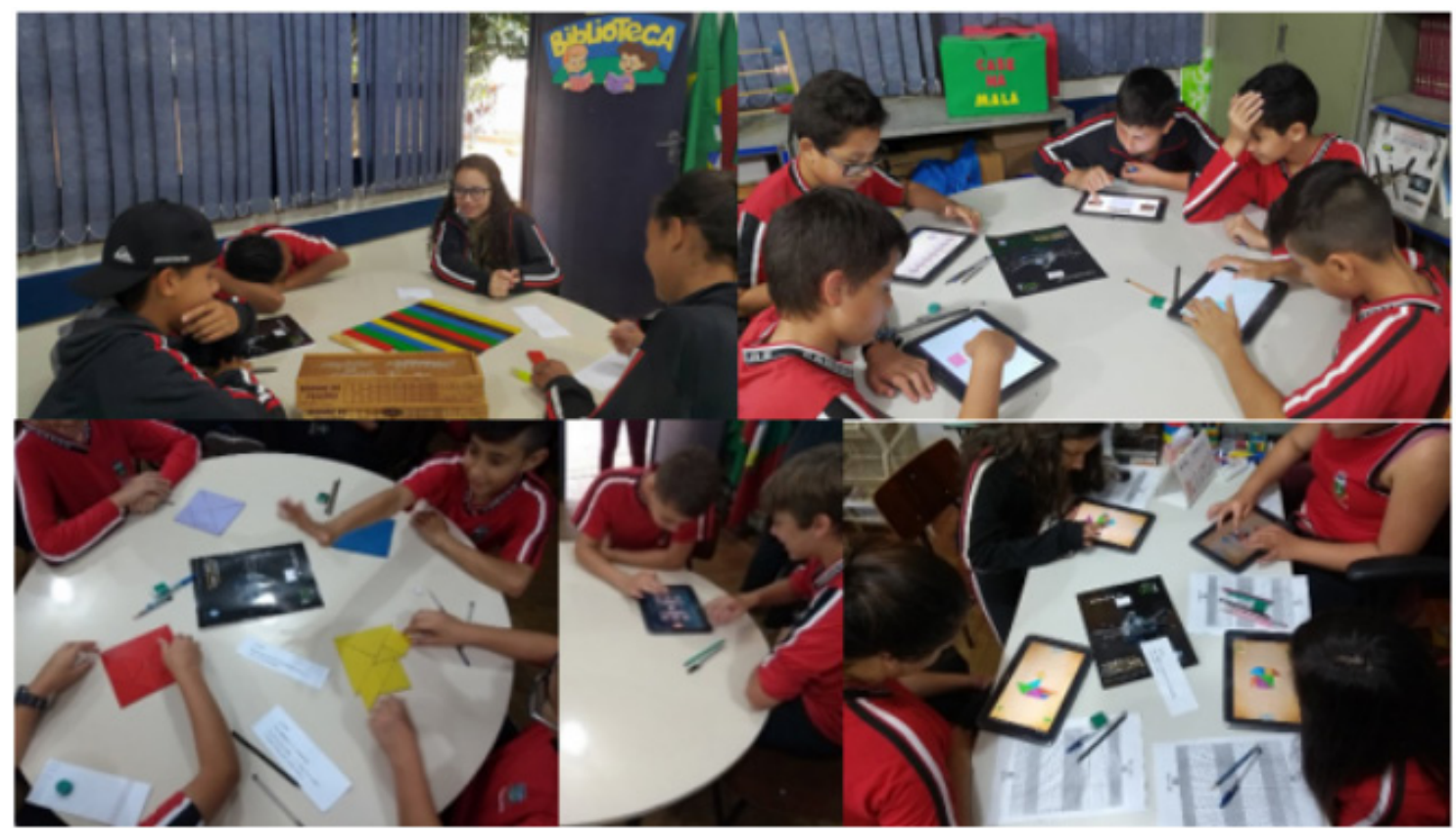

Fonte: Elaborada pelos autores. 
As atividades de preferência dos estudantes foram aquelas que utilizavam tecnologia, em especial, Math Duel e Simply Fractions.

Os acadêmicos realizaram as atividades demonstrando ter domínio de classe e capacidade de organização, comunicação e coordenação de grupos. Além disso, eles se preocuparam em utilizar recursos didáticos diversos (como materiais concretos, atividades lúdicas e aplicativos) com a finalidade de tornar aprazível a atividade lúdica, criando um ambiente de aprendizagem prazeroso e motivador.

Analisando a ação realizada, percebe-se que os acadêmicos extensionistas procuraram utilizar atividades que despertassem a curiosidade dos estudantes e os estimulassem a aplicar os conceitos matemáticos em novas situações, tanto individuais como coletivas.

Dentre as contribuições dessas atividades para a comunidade assistida, pode-se destacar que a ação buscou desenvolver:

- o pensamento lógico e o espírito crítico para identificar e resolver problemas formulando perguntas e hipóteses, aplicando conceitos matemáticos;

- a aptidão para dar sentido a problemas numéricos e para reconhecer as operações que são necessárias à sua resolução;

- a aptidão para efetuar cálculos mentalmente;

- o reconhecimento e a utilização de diferentes formas de representação dos elementos dos conjuntos numéricos, assim como as propriedades nesses conjuntos;

- a aptidão para reconhecer e analisar propriedades de figuras geométricas;

- a predisposição para procurar e explorar padrões geométricos;

- a predisposição para procurar padrões e regularidades e para formular generalizações em situações diversas, em contextos algébricos e geométricos;

- a aptidão para analisar as relações numéricas de uma situação, explicitá-las em linguagem corrente e representá-las por meio de diferentes processos, e

- a promoção da socialização (de ideias) entre os indivíduos de cada comunidade.

Analisando as interações e atividades realizadas pelos sete acadêmicos extensionistas durante o desenvolvimento do projeto, bem como as cinco ações realizadas, com a finalidade de diagnosticar os problemas e os 
benefícios desta ação, encontraram-se, como elementos significativos deste projeto, o engajamento dos acadêmicos participantes, o desenvolvimento de conteúdos matemáticos por meio de atividades diferenciadas do cotidiano escolar, a participação da comunidade externa (comunidade escolar) e o efeito multiplicador de conhecimento.

Como aspectos negativos, destacou-se a baixa aderência de acadêmicos à proposta, incluindo a desistência (ou não participação) da metade dos acadêmicos vinculados ao projeto.

Dentre os benefícios do projeto de extensão universitária para a formação dos acadêmicos, destacam-se: a ampliação de conhecimentos, o desenvolvimento da autonomia de estudo independente e o desenvolvimento das habilidades de: comunicar-se oralmente, partilhar conhecimentos, trabalhar em equipe, planejar sequências de atividades didáticas; analisar, selecionar e produzir materiais didáticos.

E dentre as contribuições do projeto de extensão para a comunidade escolar, destacam-se a ampliação de conhecimentos e a integração com a universidade. Além disso, é importante salientar que os participantes das oficinas pedagógicas são potenciais multiplicadores desses conhecimentos, visto que, entre os 270 indivíduos, 56 são profissionais (ou futuros profissionais) da educação, tornando notório o impacto social promovido pela extensão universitária.

\section{CONCLUSÃO}

As ações extensionistas desenvolvidas no projeto realizado demonstraram ser possível que estudantes em formação inicial realizem, com orientação de um professor da universidade, projetos de extensão junto à comunidade escolar. É importante que os acadêmicos deparem com exemplos de ações que podem ser desenvolvidas nas comunidades em que irão atuar futuramente.

Os resultados obtidos e as reflexões realizadas levam a acreditar que uma das possibilidades viáveis para a inserção de atividades extensionistas no currículo de um curso de Licenciatura em Matemática é a modalidade de projetos de extensão universitária. Considera-se que as atividades extensionistas são projetos quando realizadas em processos contínuos de caráter educativo e social, com objetivo específico e prazo determinado. Esses projetos devem contemplar temáticas de interesse para a comunidade escolar, envolvendo, preferencialmente, pais, alunos ou professores no processo de ensino e aprendizagem da matemática, sendo realizadas a difusão e a socialização 
dos conhecimentos adquiridos e produzidos pelas pesquisas realizadas na academia.

Com relação às possibilidades de desenvolver ações na formação inicial de professores de matemática para que se viabilize a extensão universitária na educação básica ou na comunidade escolar, integradas ao currículo do curso de Matemática Licenciatura, pode-se verificar, por meio da realização de um experimento, que, em um projeto de extensão, ocorre a indissociabilidade entre ensino, pesquisa e extensão, visto que propõe um processo que capacita o futuro profissional do magistério em conhecimentos, habilidades e atitudes para desenvolver a sua prática profissional, promovendo uma reflexão sobre a própria prática docente, cuja meta principal, segundo Imbernón (2012), é aprender a interpretar, autoavaliar, compartilhar, compreender e refletir sobre o ensino e a realidade social e profissional.

E, com relação à visão de acadêmicos participantes de um projeto de extensão, no que concerne à contribuição desta atividade para a sua formação e à divulgação dos conhecimentos adquiridos na academia para a comunidade escolar, pode-se verificar que ocorrem mudanças na vida acadêmica a partir do momento em que o estudante se envolve em atividades de extensão.

A pesquisa verificou que os acadêmicos, por intermédio da participação em um projeto de extensão, desenvolvem a capacidade de organizar sequências didáticas que favoreçam a motivação para a aprendizagem, considerando as necessidades educativas e os interesses de crianças e adolescentes, bem como a ampliação de seus conhecimentos prévios.

Os principais pontos a serem destacados durante o desenvolvimento do projeto são: o engajamento dos acadêmicos participantes, o desenvolvimento de conteúdos matemáticos por meio de atividades diferenciadas do cotidiano escolar, a participação da comunidade externa (comunidade escolar) e o efeito multiplicador de conhecimento.

Outro aspecto destacado pela pesquisa é que as atividades extensionistas colocam a comunidade escolar em contato com o conhecimento gerado na academia.

Considera-se, portanto, que a extensão universitária é um meio facilitador do processo de ensino e aprendizagem, visto que ela favorece a investigação e proporciona um maior protagonismo por parte do aluno, promovendo a autoaprendizagem, proporcionando a formação de profissionais criativos, capazes de inovar, prever situações novas e resolver problemas não previstos na graduação. 


\section{The Curricularization of Education and Public Outreach at a Mathematics Teacher Education Course}

Abstract: This article presents a selected topic of the dissertation titled Curricularização da extensão universitária: possibilidades em um curso de Matemática Licenciatura [Curricularization of Education and Public Outreach: Possibilities in a Mathematics Licensure Program], which investigated the possibilities of incorporating outreach activities to the curriculum of an undergraduate mathematics licensure program, based on a decision by the Ministry of Education that education and public outreach be incorporated in at least $10 \%$ of total undergraduate credits. The research consisted of a qualitative study in which we developed an outreach project with seven undergraduate students at the ULBRA's undergraduate mathematics program. The project was attended by 270 people from the local community. According to our results and reflections thereof, we found that a viable way to incorporate education and public outreach activities to the curriculum of an undergraduate mathematics licensure program is through the outreach project modality.

Keywords: Education and public outreach. Initial teacher education. Outreach projects. 


\section{La curricularización de la extensión universitaria en un curso de formación de profesores de matemáticas}

Resumen: El artículo presenta un recorte de la disertación Curricularização da extensão universitária: possibilidades em um curso de Matemática Licenciatura [Curricularización de la extensión universitaria: posibilidades en un curso de grado de Profesorado en Matemáticas], realizada con el objetivo de investigar las posibilidades de introducir actividades extensionistas en el currículo de un curso de grado de Profesorado en Matemáticas, teniendo como premisa la decisión del Ministerio de Educación de Brasil de que la extensión se incorpore en, al menos, el 10 \% de los créditos de formación académica. La investigación se configuró como un estudio de naturaleza cualitativa, en la cual se desarrolló un proyecto de extensión con la participación de siete académicos del curso de Matemáticas de la Universidad Luterana de Brasil (Ulbra) y 270 participantes de la comunidad externa. Los resultados obtenidos y las reflexiones hechas llevan a considerar que una de las posibilidades viables para introducir actividades extensionistas en el currículo de un curso de grado de Profesorado en Matemáticas es la modalidad de proyectos de extensión.

Palabras clave: Extensión universitaria. Formación inicial de profesores. Proyectos extensionistas. 


\section{REFERÊNCIAS}

ANDRÉ, Marli Eliza Dalmazo Afonso de. Texto, contexto e significados: algumas questões na análise de dados qualitativos. Cadernos de Pesquisa, São Paulo, n. 45, p. 66-71, 1983.

BEZERRA, Edileusa Medeiros. Gestão de projetos extensionistas: um estudo de caso na extensão da Universidade do Estado da Bahia. 2013. 98 p. Relatório de Pesquisa (Mestrado Profissional)-Programa de Pós-graduação em Gestão e Tecnologias Aplicadas à Educação, Universidade do Estado da Bahia, Salvador, 2013.

BRASIL. Lei no 13.005 , de 25 de junho de 2014. Aprova o Plano Nacional de Educação - PNE e dá outras providências. Brasília: 2014.

. Parecer CNE/CES 1.302/2001. Diretrizes Curriculares Nacionais para os Cursos de Matemática, Bacharelado e Licenciatura. Brasília: Ministério da Educação, 2001.

- Resolução no 02, de 1을 de julho de 2015. Define as Diretrizes Curriculares Nacionais para a formação inicial em nível superior (cursos de licenciatura, cursos de formação pedagógica para graduados e cursos de segunda licenciatura) e para a formação continuada. Brasília: Conselho Nacional de Educação, 2015.

D’AMBRÓSIO, Ubiratan. Desafios da educação matemática no novo milênio. Educação Matemática em Revista, São Paulo, ano 8, n. 11, p. 14-17, 2001.

DEUS, Adélia Meireles de; CUNHA, Djanira do Espírito Santo Lopes; MACIEL, Emanoela Moreira. Estudo de caso na pesquisa qualitativa em educação: uma metodologia. In: ENCONTRO DE PESQUISA EM EDUCAÇÃO DA UFPI, 6., 2010, Teresina. Anais... Teresina: UFPI, 2010. Disponível em: 〈leg.ufpi.br/ subsiteFiles/ppged/arquivos/files/VI.../GT.../GT_01_14.pdf 〉. Acesso em: $1^{\underline{0}}$ mar. 2016.

FERNÁNDEZ, Josefa Cuesta. Una experiencia en la formación didáctica de los futuros maestros. Reflexiones en torno a sus propósitos, princípios, obstáculos y tentativas. Investigación en la escuela, Sevilla, Espanha, n. 35, 1998.

FORPROEX. Política Nacional de Extensão Universitária. Manaus, 2012.

GARCIA, Berenice R. Z.; BOHN, Letícia R. D.; ARAÚJO, Maria Inês S. Universidade e extensão: uma relação dialógica entre formação profissional e compromisso 
social. In: SÍVERES, Luiz (Org.). A extensão universitária como um princípio de aprendizagem. Brasília: Liber Livro, 2013.

GÓMEZ, Angel Pérez. O pensamento prático do professor: a formação do professor como profissional reflexivo. In: NÓVOA, António (Coord.). Os professores e sua formação. 2. ed. Lisboa: Publicações Dom Quixote, 1995.

GROENWALD, Claudia Lisete Oliveira. Cadernos Universitários: Estágio Supervisionado em Matemática I. Canoas: Editora Ulbra, 2005.

IMBERNÓN, Francisco. Inovar o ensino e a aprendizagem na universidade. Trad. Silvana Cobucci Leite. São Paulo: Cortez, 2012.

MARTINHAGO, Laiza. A formação inicial dos professores de Matemática. 2009. 71 p. Monografia (Especialização em Educação Matemática)-Universidade do Extremo Sul Catarinense (Unesc), Criciúma, 2009.

MARTINS, Cristina. O uso de portfólios na formação inicial de professores de matemática. Quadrante - Revista de Investigação em Educação Matemática, v. 13, n. 1, 2004.

OLIVEIRA, Hélia. Percursos de identidade do professor de Matemática em início de carreira: o contributo da formação inicial. Quadrante - Revista de Investigação em Educação Matemática, v. 13, n. 1, 2004.

PERRENOUD, Philippe. Dez novas competências para uma nova profissão. Pátio - Revista Pedagógica, Porto Alegre, n. 17, p. 8-12, maio/jul. 2001. Disponível em: 〈https://www.unige.ch/fapse/SSE/teachers/perrenoud/php_ main/php_2001/2001_23.html>. Acesso em: 5 fev. 2017.

PINILLA, Martha Isabel Fandiño. Currículo, evaluación y formación docente em Matemática. Bogotá: Cooperativa Editorial Magisterio, 2006.

SÍVERES, Luiz. O princípio da aprendizagem na extensão universitária. In: (Org.). A extensão universitária como um princípio de aprendizagem. Brasília: Liber Livro, 2013.

SOUSA, Ana Luiza Lima. A história da extensão universitária. Campinas: Editora Alínea, 2010.

VEIGA, Ilma Passos Alencastro. A aventura de formar professores. 2. ed. Campinas: Papirus, 2014. 


\section{SOBRE AS AUTORAS}

Ursula Tatiana Timm é mestre em Ensino de Ciências e Matemática pelo PPGECIM da Universidade Luterana do Brasil (Ulbra). Atualmente é professora do curso de Matemática da Ulbra.

E-mail: timm.ursula@gmail.com.

Claudia Lisete Oliveira Groenwald é doutora em Ciências da Educação pela Pontifícia de Salamanca, na Espanha. Atualmente é professora do curso de Matemática Licenciatura e do PPGECIM da Universidade Luterana do Brasil (Ulbra).

E-mail: claudiag@ulbra.br.

Recebido em: abril de 2018

Aceito em: maio de 2018 